\title{
Orchestration of Ion Channels and Transporters in Neocortical Development and Neurological Disorders
}

\author{
Yuki Bando ${ }^{1 *}$, Masaru Ishibashi ${ }^{2}$, Satoru Yamagishi' ${ }^{1}$ Atsuo Fukuda ${ }^{2}$ and Kohji Sato ${ }^{1}$ \\ ${ }^{1}$ Department of Organ and Tissue Anatomy, Hamamatsu University School of Medicine, Hamamatsu, Japan, ${ }^{2}$ Department \\ of Neurophysiology, Hamamatsu University School of Medicine, Hamamatsu, Japan
}

Electrical activity plays crucial roles in neural circuit formation and remodeling. During neocortical development, neurons are generated in the ventricular zone, migrate to their correct position, elongate dendrites and axons, and form synapses. In this review, we summarize the functions of ion channels and transporters in neocortical development. Next, we discuss links between neurological disorders caused by dysfunction of ion channels (channelopathies) and neocortical development. Finally, we introduce emerging optical techniques with potential applications in physiological studies of neocortical development and the pathophysiology of channelopathies.

OPEN ACCESS

Edited by:

Hidenobu Mizuno,

Kumamoto University, Japan

Reviewed by:

Corette J. Wierenga,

Utrecht University, Netherlands

*Correspondence:

Yuki Bando

bando@hama-med.ac.jp

Specialty section:

This article was submitted to

Neural Technology,

a section of the journal

Frontiers in Neuroscience

Received: 01 December 2021

Accepted: 24 January 2022

Published: 14 February 2022

Citation:

Bando Y, Ishibashi M,

Yamagishi S, Fukuda A and Sato $K$

(2022) Orchestration of Ion Channels

and Transporters in Neocortical

Development and Neurological

Disorders.

Front. Neurosci. 16:827284.

doi: 10.3389/fnins.2022.827284
Keywords: cerebral cortex, neurogenesis, neuronal migration, dendrite, axon, ion channel, transporter, channelopathy

\section{INTRODUCTION}

Precise formation of neocortical circuits is essential for brain function. The cerebral cortex consists of six layers. Its laminar structure is formed in an "inside-out" manner; layer 6 is formed first, followed by formation of upper layers above the lower layers. Neocortical excitatory neurons are produced from neural progenitor cells in the ventricular zone (VZ). During neurogenesis, intermediate progenitors are produced from radial glia. Intermediate progenitors then produce or differentiate into excitatory neurons (Hevner, 2006). The newly born neurons migrate toward the marginal zone (MZ).

During migration, neurons dynamically change their morphology. Neocortical excitatory neurons slowly move in the subventricular zone (SVZ) and the intermediate zone (IZ) with small processes in multiple directions (multipolar migration) (Tabata and Nakajima, 2003). Then, migrating neurons change their shape at the border between the IZ and the cortical plate (CP) to a bipolar shape with long leading processes and short trailing processes, and migrate along the radial axis toward the cortical surface (Nadarajah et al., 2003). Finally, neurons stop migration below the MZ, and elongate dendrites and axons (Tissir and Goffinet, 2003; Mizuno et al., 2007, 2014). The molecular mechanisms of neocortical development have been intensely studied (Tessier-Lavigne and Goodman, 1996; O'Leary and Nakagawa, 2002; Hevner, 2006; Molyneaux et al., 2007; Kawauchi and Hoshino, 2008; Kawauchi, 2012; Marín, 2012). As well as genetic programs, electrical activity and $\mathrm{Ca}^{2+}$ signaling are also crucial for these processes (Katz and Shatz, 1996; Spitzer, 2006). Recent reports showed that dysfunction of ion channels or transporters disrupts neocortical development by altering electrical properties and $\mathrm{Ca}^{2+}$ signaling and may be linked to neurological disorders 
(Kullmann, 2010; Schmunk and Gargus, 2013; Guglielmi et al., 2015; Heyes et al., 2015; Kahle et al., 2016). In this review, we summarize how ion channels and transporters regulate electrical properties and $\mathrm{Ca}^{2+}$ signaling during neocortical development, focusing on excitatory neurons. Next, we discuss possible links between abnormal electrical signaling caused by dysfunction of ion channels or transporters and neurological disorders. Finally, we discuss the potential application of emerging optical techniques to address remaining issues related to the physiological mechanisms of neocortical development and the pathophysiology of channelopathies in vivo.

\section{Electrical Signaling During Neocortical Development}

The roles of electrical signaling in axonal and dendritic growth and remodeling during late developmental stages have been intensely studied (Katz and Shatz, 1996; Price et al., 2006). Further studies revealed that electrical signaling is also crucial for early cortical development including neuronal proliferation, differentiation, and migration (Spitzer, 2006). These studies suggest that temporal regulation of electrical signals is critical for neocortical development (Figure 1). We discuss the details below.

\section{Neurogenesis, Differentiation, and Cell Fate Specification}

Radial glial cells express various ion channels such as $\alpha$-amino3-hydroxy-5-methyl-4-isoxazolepropionic acid (AMPA) and kainate type glutamate receptor, $\gamma$-aminobutyric acid type $\mathrm{A}$ receptor $\left(\mathrm{GABA}_{A} \mathrm{R}\right)$, voltage-gated $\mathrm{Ca}^{2+}$ channels (VGCCs), P2X receptor, and connexin 26 and 43, but not N-methylD-aspartate (NMDA) type glutamate receptor (LoTurco et al., 1995; Bittman and LoTurco, 1999). The electrical properties of neural progenitors are distinct from those of mature neurons (Liu et al., 2010). Neural progenitors are non-spiking because of a small voltage-dependent $\mathrm{Na}^{+}$current. Their resting potential is about $-75 \mathrm{mV}$, and their input resistance is about $350 \mathrm{M} \Omega$. Activation of AMPA and kainate receptor and $\mathrm{GABA}_{A} \mathrm{R}$ inhibits DNA synthesis by depolarizing membrane potentials (LoTurco et al., 1995). Further studies revealed that $\mathrm{Ca}^{2+}$ transients are required for the transition from $\mathrm{G} 1$ to $\mathrm{S}$ phase by releasing adenosine triphosphate (ATP) from progenitor cells through gap junction/hemichannels resulting in activation of $\mathrm{P} 2 \mathrm{X}$ receptors. This indicates that temporal patterns of $\mathrm{Ca}^{2+}$ signaling are critical for cell cycle progression and neurogenesis (Weissman et al., 2004; Liu et al., 2010). A recent study demonstrated that activation of $\mathrm{GABA}_{A} \mathrm{R}$ promotes the transition from apical to basal progenitor cells by elevating of the intracellular $\mathrm{Ca}^{2+}$ concentration, suggesting that the excitatory action of GABAergic signals regulates differentiation of neural progenitors (Tochitani et al., 2021).

Interestingly, electrical activity also affects the cell fate of cortical excitatory neurons. A gain-of-function mutation of an L-type VGCC, CACNA1C $\left(\mathrm{Ca}_{v} 1.2\right)$ reduces the fraction of Satb2positive callosal projection neurons and increases the fraction of Ctip2-positive corticofugal projection neurons in layer 5 (Paşca et al., 2011). Recently, Vitali et al. (2018) showed that regulation of the resting potential is important for specification of upper layer neurons. Neural progenitors are more hyperpolarized at embryonic day 15 (E15) than at E14, and premature hyperpolarization of progenitors by expression of an inward rectifier $\mathrm{K}^{+}$channel, KCNJ2 (Kir2.1), decreases the fraction of ROR $\beta$-positive layer 4 neurons and increases the fraction of Brn2-positive layer 2/3 neurons. There remain interesting questions about how electrical signals regulate transcription networks and how plastic production of neuronal populations is during cortical development.

\section{Neuronal Migration}

Newly born neurons have a more depolarized resting potential than neural progenitors $(\sim-60 \mathrm{mV})$, drastically increased input resistance $(\sim 3 \mathrm{G} \Omega)$, and less frequent spontaneous $\mathrm{Ca}^{2+}$ transients in the SVZ and IZ (Figure 1; Bando et al., 2014). Immature neurons express $\mathrm{GABA}_{A} \mathrm{R}$, NMDAR, CACNA1C, and CACNA1D $\left(\mathrm{Ca}_{v} 1.3\right)$. The expression levels of CACNA1C and CACNA1D are higher in the IZ and CP than in the VZ (Kamijo et al., 2018; Horigane et al., 2021). In the IZ, glutamate promotes migration into the $\mathrm{CP}$ via NMDAR (Behar et al., 1999). Around the border between the IZ and subplate (SP), migrating excitatory neurons show more frequent and larger $\mathrm{Ca}^{2+}$ transients than neurons in the lower IZ (Figure 1), because of activation of NMDAR by SP neurons. The increase of $\mathrm{Ca}^{2+}$ transients promotes the multipolar-to-bipolar transition of migrating upper layer neurons at E17 and E18 (OhtakaMaruyama et al., 2018; Horigane et al., 2021). During locomotion in the $\mathrm{CP}$, the frequency of spontaneous $\mathrm{Ca}^{2+}$ transients decreases, and migrating neurons show more frequent $\mathrm{Ca}^{2+}$ transients after reaching the MZ (Figure 1; Bando et al., 2014, 2016). Suppression of spontaneous activity by blocking $\mathrm{GABA}_{A} \mathrm{R}$ results in acceleration of radial migration and invasion of neurons into the MZ (Behar et al., 2000; Heck et al., 2007; Furukawa et al., 2014). A tandem pore domain $\mathrm{K}^{+}$channel, KCNK9 $\left(\mathrm{K}_{2 P} 9.1\right)$ promotes migration by suppressing spontaneous $\mathrm{Ca}^{2+}$ transients (Bando et al., 2014). Nakagawa-Tamagawa et al. (2021) reported that a disease-associated mutation of CACNA1C causes migration arrest. Furthermore, the strong elevation of spontaneous activity during early developmental stages in the neocortex stops neuronal migration, and induces dendritic branch formation (Bando et al., 2016). These results show that spontaneous $\mathrm{Ca}^{2+}$ transients should be kept low during radial migration and that an increase of $\mathrm{Ca}^{2+}$ signaling acts as a stop signal in cortical excitatory neurons. Electrical signals induce elevation of intracellular $\mathrm{Ca}^{2+}$, which functions as a second messenger; it activates multiple $\mathrm{Ca}^{2+}$-dependent enzymes, followed by activation of downstream signaling cascades, and also regulates cytoskeletal dynamics and exocytosis. Taken together, these findings show that properly regulated $\mathrm{Ca}^{2+}$ signaling at each developmental stage is critical for neocortical formation (Manent and Represa, 2007; Zheng and Poo, 2007; Uhlén et al., 2015; Horigane et al., 2019; Medvedeva and Pierani, 2020).

The correlation between the intracellular $\mathrm{Ca}^{2+}$ level and migration speed differs among cell types. Komuro and Rakic (1996) and Kumada and Komuro (2004) showed that loss of spontaneous $\mathrm{Ca}^{2+}$ transients is a stop signal for cerebellar granule cell migration. Similar to cerebellar granule cells, 


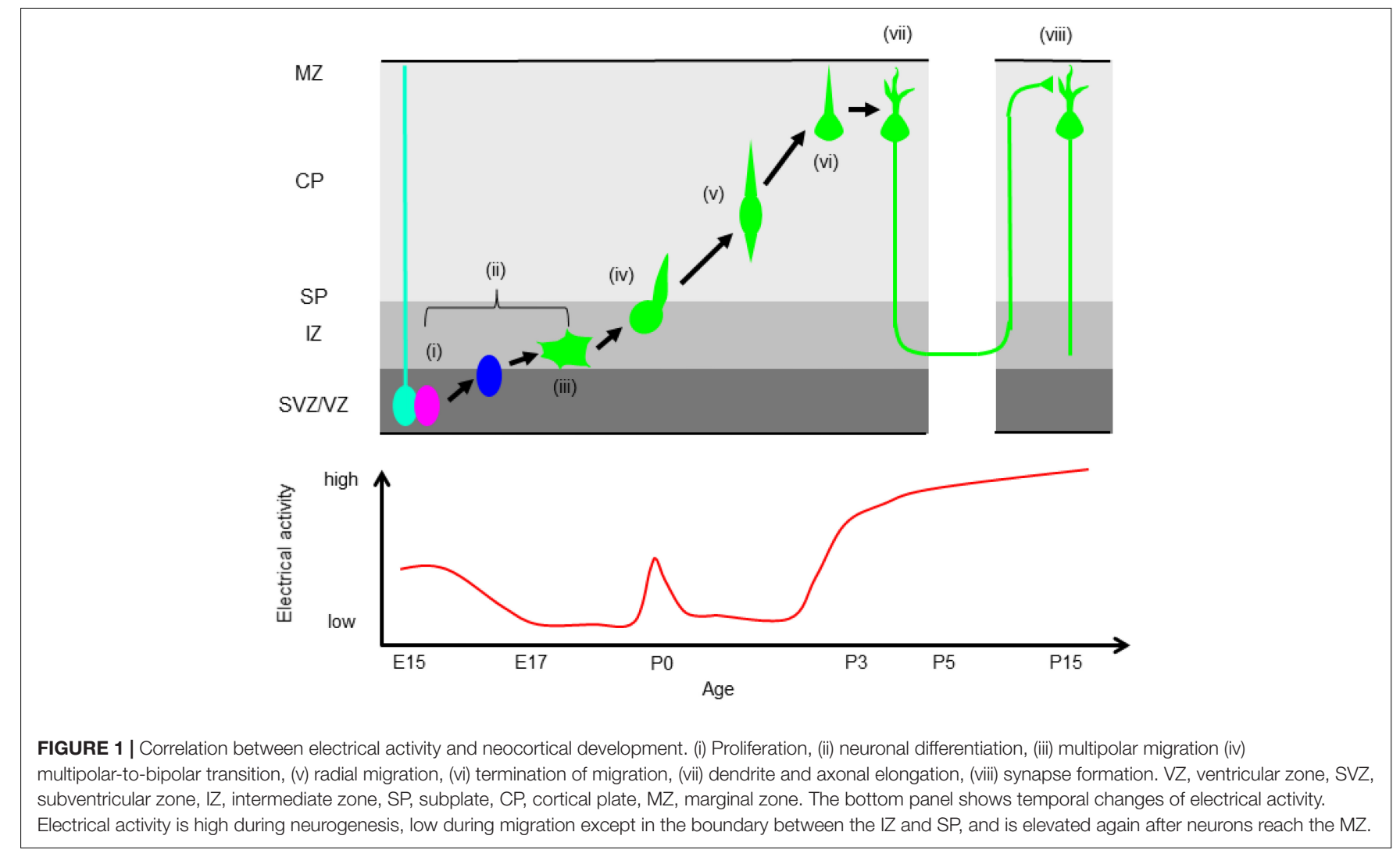

neocortical inhibitory interneurons stop migration in the absence of spontaneous $\mathrm{Ca}^{2+}$ transients caused by excitatoryto-inhibitory switching of GABAergic signaling (Bortone and Polleux, 2009). Interestingly, migration of neocortical excitatory neurons is also regulated in a $\mathrm{Ca}^{2+}$-dependent manner, but with the opposite mechanism as described above. It remains unclear what underlies the difference in $\mathrm{Ca}^{2+}$-dependency between migration of cortical excitatory and cortical inhibitory interneurons/cerebellar granule cells.

\section{Dendrite Formation, Axonal Projection, and Synapse Formation}

Post-migratory neurons become electrically mature; expression of voltage-gated $\mathrm{Na}^{+}$channels increases (peak $\mathrm{Na}^{+}$current: $90 \mathrm{pA}$ at $\mathrm{P} 0$, and $\sim-800 \mathrm{pA}$ at $\mathrm{P} 4$ ), and neurons start firing action potentials (Picken Bahrey and Moody, 2003). Their input resistance is significantly reduced (0.6-1.6 G $\Omega$ at P4). Activitydependent formation and remodeling of dendrites, axons, and synapses have been intensely studied in multiple systems such as visual, somatosensory, olfactory, and motor systems (Hubel et al., 1977; Iwasato et al., 1997; Wong and Ghosh, 2002; Hanson and Landmesser, 2004; Serizawa et al., 2006). Electrical activity is crucial for projection and arborization of thalamocortical axons (Antonini and Stryker, 1993; Uesaka et al., 2007; Mire et al., 2012; Antón-Bolaños et al., 2019). Mire et al. (2012) reported that temporal patterns of thalamocortical neuron activity are crucial for axon guidance through regulation of the axon guidance molecule, Robol. The activity of thalamocortical axons affects spatial patterning of dendrites in layer 4 neurons through activation of NMDAR (Mizuno et al., 2014). This demonstrates that the cooperative activity of pre- and postsynaptic neurons shapes the thalamocortical circuit (Yamada et al., 2010; Mizuno et al., 2014). Excitatory GABA is essential for dendrite formation in layer $2 / 3$ pyramidal neurons. In layer $2 / 3$ pyramidal neurons, excitatory-to-inhibitory switching of GABA occurs between postnatal day 6 (P6) and P14. Premature excitatory-to-inhibitory switching of GABA by expressing $\mathrm{K}-\mathrm{Cl}$ co-transporter 2 (KCC2) suppresses dendritic growth in layer $2 / 3$ pyramidal neurons (Cancedda et al., 2007). Suppression of neural activity by expressing KCNJ2 significantly reduces dendritic growth, and layer-specific projection of callosal axons in cortical layer 2/3 neurons (Cancedda et al., 2007; Mizuno et al., 2007, 2010; Wang et al., 2007). Expression of a gain-of-function CACNA1C mutant also disrupts callosal axon projection (Nakagawa-Tamagawa et al., 2021). These reports suggest that the optimal frequency of electrical activity is critical for callosal axon projection. A further study revealed that layer-specific projection of callosal axons requires postsynaptic activity (Mizuno et al., 2010).

\section{Potential Links Between Dysfunction of Ion Channels/Transporters and Neurological Disorders}

Dysfunction of ion channels or transporters is associated with neurological and psychiatric disorders such as epilepsy, autism spectrum disorder, and schizophrenia (Kullmann, 2010; 
Schmunk and Gargus, 2013; Guglielmi et al., 2015; Heyes et al., 2015). In some patients and mouse models of channelopathies, malformations of cortical development are observed. Ion channels and transporters play crucial roles in neocortical development; therefore, developmental defects might underlie the symptoms of channelopathies. We describe some examples below.

NMDAR is a key ligand-gated ion channel for any developmental events and plasticity in the nervous system. Mutations of NMDAR are associated with a wide variety of neurological and psychiatric disorders such as schizophrenia, epilepsy, and depression (Kalia et al., 2008; Hardingham and Do, 2016; Adell, 2020).

Tandem pore domain $\mathrm{K}^{+}$channels suppress neuronal excitability by hyperpolarizing the resting membrane potential and reducing membrane resistance. A dominant-negative mutation of KCNK9 was found in patients with BirkBarel syndrome, a maternally transmitted genomic imprinting disorder characterized by severe intellectual disability, hypotonia, and dysmorphism in the form of an elongated face (Barel et al., 2008). Knock-down or functional blockade of KCNK9 by expressing a disease-associated dominant-negative mutant channel impairs neuronal migration in the developing neocortex (Bando et al., 2014). Since migration defect is associated with many neurological and psychiatric disorders (Ross and Walsh, 2001; LoTurco and Bai, 2006; Ben-Ari, 2008), migration defect might be a candidate of its pathogenesis. Interestingly, another tandem pore domain $\mathrm{K}^{+}$channel, KCNK2 $\left(\mathrm{K}_{2 P} 2.1\right)$ might be linked to brain aging. Le Guen et al. (2019) investigated the genetic influence on sulcal widening in elderly individuals. They found that the regulatory region of KCNK2 influences sulcal widening, suggesting a potential link between KCNK2 expression and brain atrophy (Le Guen et al., 2019).

CACNA1C, a L-type VGCC, is associated with Timothy syndrome, which is characterized by long QT syndrome in the heart, autism spectrum disorder, and mild dysmorphism of the face. Several gain-of-function mutations of CACNA1C have been found in patients (Heyes et al., 2015). Diseaseassociated mutant CACNA1C disrupts neocortical development, including cell fate specification of cortical projection neurons, radial migration, dendrite formation/remodeling, and callosal axon projection (Paşca et al., 2011; Kamijo et al., 2018; Horigane et al., 2021; Nakagawa-Tamagawa et al., 2021). Downregulation of CACNA1C is also associated with psychiatric disorders. A lossof function mutation and lower expression level of CACNA1C were found in patients with schizophrenia by genome-wide screening of disease-associated mutations (Purcell et al., 2014; Roussos et al., 2014; Heyes et al., 2015). Conditional knockout of CACNA1C impairs neurite growth in cultured cortical neurons (Kamijo et al., 2018); therefore, downregulation of CACNA1C might cause psychotic symptoms by disrupting neocortical development.

Excitatory-to-inhibitory switching of GABA is mediated by a change in expression of $\mathrm{Cl}^{-}$transporters. During the early developmental stage, $\mathrm{Na}-\mathrm{K}-\mathrm{Cl}$ co-transporter 1 (NKCC1), which transports $\mathrm{Cl}^{-}$into the cell, is highly expressed. In the later stage, expression of NKCC1 decreases and expression of KCC2, which transports $\mathrm{Cl}^{-}$out of the cell, is elevated. Excitatoryto-inhibitory switching of GABA plays important roles in neocortical development. Excitatory GABA regulates neuronal production, migration, and dendrite formation (Cancedda et al., 2007; Heck et al., 2007; Tochitani et al., 2021). Dysfunction of KCC2 or $\mathrm{GABA}_{A} \mathrm{R}$ is associated with epilepsy (Kaila et al., 2014; Kahle et al., 2016; Maljevic et al., 2019; Watanabe et al., 2019).

Similar to Timothy syndrome, mutations of ion channels associated with cardiac disorders can affect neocortical neural circuit formation. For example, expression of a gain-of-function KCNJ2 mutant that causes atrial fibrillation significantly reduces branching of callosal axons in the upper layers in the contralateral hemisphere (Mizuno et al., 2007).

In patients with other neurological channelopathies, malformation of cortical development was observed. Periventricular nodular heterotopia was observed in some patients with sleep-related hypermotor epilepsy and point mutations in the sodium-activated $\mathrm{K}^{+}$channel KCNT1 (Slack or $\mathrm{K}_{\mathrm{Na}}$ 1.1) (Rubboli et al., 2018). Polymicrogyria was observed in patients with drug-resistant epilepsy and mutations in the $\mathrm{Ca}^{2+}$ activated $\mathrm{K}^{+}$channel KCNMA1 (BK channel) (Graber et al., 2021). Periventricular nodular heterotopia and focal cortical dysplasia were observed in patients with Dravet syndrome and mutations in the voltage-gated $\mathrm{Na}^{+}$channel SCN1A $\left(\mathrm{Na}_{v} 1.1\right)$ (Barba et al., 2014). As discussed above, some neurological disorders are accompanied by malformation of the cortical gyrus. Genetically modified ferret and common marmoset are good experimental models to study the physiological mechanisms of gyrus formation (Sasaki et al., 2009; Kawasaki et al., 2012; Shinmyo et al., 2017). Despite intensive efforts in developmental and clinical studies, the links between developmental defects and channelopathies remain elusive. Further studies could reveal the developmental basis of neurological channelopathies.

\section{DISCUSSION}

\section{Future Perspectives: Potential Application of Advanced Optical Techniques in Developmental Neuroscience and Pathophysiological Studies of Neurological Disorders in vivo}

To better understand the pathogenetic mechanisms of neurological channelopathies, it seems essential to investigate the roles of ion channels in neocortical development in vivo. Previously, developmental studies of the neocortex have been performed with fixed tissue and acute or cultured brain slices. Although these traditional methods are powerful tools to reveal the mechanisms of electrical activity-dependent neocortical development, there remain important problems. One of them is that secreted extracellular signals, including maternal signals, are washed out in the slice condition. For instance, taurine, a weak agonist of $\mathrm{GABA}_{A} \mathrm{R}$, plays important roles in the development of the embryonic nervous system (Kilb and Fukuda, 2017). Taurine is provided to the embryo from the mother through the placenta because mouse embryos do not 
synthesize taurine (Sturman et al., 1977; Sturman, 1981). Thus, monitoring neocortical development in the intact brain is the next step. To achieve this, optical methods seem ideal. Recently, in vivo two-photon imaging of the neonatal and embryonic mouse neocortex has been achieved (Mizuno et al., 2014, 2018; Yuryev et al., 2016; Kawasoe et al., 2020; Hattori et al., 2020). Voltage imaging is promising to monitor electrical signals in the developing neocortex in vivo or in utero. Recently, the performance of genetically encoded voltage indicators (GEVIs) has been improved (Gong et al., 2015; Kannan et al., 2018; Adam et al., 2019; Bando et al., 2019a,b; Piatkevich et al., 2019; Villette et al., 2019; Cornejo et al., 2022). In contrast with chemical voltage-sensitive dyes (VSDs), GEVIs can be expressed in a cell-type-specific manner, resulting in an improved signalto-noise ratio. Furthermore, long-term monitoring of electrical signals is possible using GEVIs, but not with patch-clamp recording and VSDs. Long-term monitoring of electrical activity would help researchers determine the correlation between electrical signals and developmental events such as neurogenesis, migration, and neurite growth. The combination of $\mathrm{Ca}^{2+}$ or voltage imaging and holographic photostimulation is a powerful tool to show causal links between electrical activity and developmental events (Carrillo-Reid et al., 2016). Twophoton multimodal imaging of voltage and $\mathrm{Ca}^{2+}$ in neuronal populations in vivo was recently reported (Bando et al., 2021). Application of these techniques could reveal how electrical signals are transformed into intracellular signals that drive neocortical circuit formation.

Developmental events occur in three-dimensional tissues. Thus, volumetric imaging is also important. Recently, fast threedimensional imaging techniques were developed using a spatial light modulator, an acousto-optic lens, and an electrical tunable lens (Katona et al., 2012; Yang et al., 2016, 2018; Yang and Yuste, 2017). To image deep in the brain during development, three-photon imaging and an adaptive optics are also helpful (Ji et al., 2010; Horton et al., 2013). The combination of advanced microscopy and emerging optical probes could strongly drive developmental neuroscience.

Another important issue is how developmental defects cause neurological disorders. Recent studies showed that the properties of local neocortical circuits, such as neuronal ensembles (groups of co-active neurons), are altered in mouse models of psychiatric and neurological disorders, such as schizophrenia and autism

\section{REFERENCES}

Adam, Y., Kim, J. J., Lou, S., Zhao, Y., Xie, M. E., Brinks, D., et al. (2019). Voltage imaging and optogenetics reveal behaviour-dependent changes in hippocampal dynamics. Nature 569, 413-417. doi: 10.1038/s41586-019-1166-7

Adell, A. (2020). Brain NMDA receptors in schizophrenia and depression. Biomolecules 10:947. doi: 10.3390/biom10060947

Antón-Bolaños, N., Sempere-Ferràndez, A., Guillamón-Vivancos, T., Martini, F. J., Pérez-Saiz, L., Gezelius, H., et al. (2019). Prenatal activity from thalamic neurons governs the emergence of functional cortical maps in mice. Science 364, 987-990. doi: 10.1126/science.aav7617

Antonini, A., and Stryker, M. P. (1993). Rapid remodeling of axonal arbors in the visual cortex. Science 260, 1819-1821. doi: 10.1126/science.8511592
(Fang and Yuste, 2017; Hamm et al., 2017). Simultaneous manipulation, and readout of cortical activity during behavior is promising to further elucidate the causal links between aberrant cortical activity and symptoms (Carrillo-Reid et al., 2016, 2019). Application of the recently developed two-photon mesoscope will help to clarify the alteration of cortex-wide computation at cellular resolution in animal models of disorders (Ota et al., 2021).

In summary, developmental studies revealed that dysfunction of ion channels and transporters disrupts neocortical circuit formation. Clinical studies reported potential links between neurological disorders and mutations of ion channels and transporters. However, the causal links between dysfunction of the ion channels and transporters, neocortical circuit formation, and neurological disorders are not understood. Emerging optical technologies could bridge these biophysical, developmental, and clinical studies.

\section{AUTHOR CONTRIBUTIONS}

YB organized the content. All authors wrote, revised, and approved the manuscript for publication.

\section{FUNDING}

This work was supported by the Japan Science Society, Sasakawa Scientific Research grant (YB), the Hamamatsu Society for Science and Technology (YB), the Uehara Memorial Foundation (YB), the Japan Society for the Promotion of Science Grants-inaid (20K15914 to YB; $19 \mathrm{~K} 07284$ to MI; 17K08512, 20K21499, and $21 \mathrm{H} 02655$ to SY; $21 \mathrm{H} 02661$ and $21 \mathrm{H} 05687$ to AF; and 19K22594 to KS), the Takeda Science Foundation (YB and SY), and the Hamamatsu University School of Medicine Grant-in-aid (YB, MI, and SY).

\section{ACKNOWLEDGMENTS}

We thank all laboratory members at the Department of Organ and Tissue Anatomy and Department of Neurophysiology for discussions.

Bando, Y., Grimm, C., Cornejo, V. H., and Yuste, R. (2019a). Genetic voltage indicators. BMC Biol. 17:71. doi: 10.1186/s12915-019-0682-0

Bando, Y., Sakamoto, M., Kim, S., Ayzenshtat, I., and Yuste, R. (2019b). Comparative evaluation of genetically-encoded voltage indicators. Cell Rep. 26, 802-813. doi: 10.1016/j.celrep.2018.12.088

Bando, Y., Hirano, T., and Tagawa, Y. (2014). Dysfunction of KCNK potassium channels impairs neuronal migration in the developing mouse cerebral cortex. Cereb. Cortex 24, 1017-1029. doi: 10.1093/cercor/ bhs387

Bando, Y., Irie, K., Shimomura, T., Umeshima, H., Kushida, Y., Kengaku, M., et al. (2016). Control of spontaneous $\mathrm{Ca} 2+$ transients is critical for neuronal maturation in the developing neocortex. Cereb. Cortex 26, 106-117. doi: 10. 1093/cercor/bhu180 
Bando, Y., Wenzel, M., and Yuste, R. (2021). Simultaneous two-photon imaging of action potentials and subthreshold inputs in vivo. Nat. Commun. 12:7229. doi: 10.1038/s41467-021-27444-9

Barba, C., Parrini, E., Coras, R., Galuppi, A., Craiu, D., Kluger, G., et al. (2014). Cooccurring malformations of cortical development and SCN1A gene mutations. Epilepsia 55, 1009-1019. doi: 10.1111/epi.12658

Barel, O., Shalev, S. A., Ofir, R., Cohen, A., Zlotogora, J., Shorer, Z., et al. (2008). Maternally inherited Birk Barel mental retardation dysmorphism syndrome caused by a mutation in the genomically imprinted potassium channel KCNK9. Am. J. Hum. Genet. 83, 193-199. doi: 10.1016/j.ajhg.2008.07.010

Behar, T. N., Schaffner, A. E., Scott, C. A., Greene, C. L., and Barker, J. L. (2000). GABA receptor antagonists modulate postmitotic cell migration in slice cultures of embryonic rat cortex. Cereb. Cortex 10, 899-909. doi: 10.1093/ cercor/10.9.899

Behar, T. N., Scott, C. A., Greene, C. L., Wen, X., Smith, S. V., Maric, D., et al. (1999). Glutamate acting at NMDA receptors stimulates embryonic cortical neuronal migration. J. Neurosci. 19, 4449-4461. doi: 10.1523/JNEUROSCI.1911-04449.1999

Ben-Ari, Y. (2008). Neuro-archaeology: pre-symptomatic architecture and signature of neurological disorders. Trends Neurosci. 31, 626-636. doi: 10.1016/ j.tins.2008.09.002

Bittman, K. S., and LoTurco, J. J. (1999). Differential regulation of connexin 26 and 43 in murine neocortical precursors. Cereb. Cortex 9, 188-195. doi: 10.1093/ cercor/9.2.188

Bortone, D., and Polleux, F. (2009). KCC2 expression promotes the termination of cortical interneuron migration in a voltage-sensitive calcium-dependent manner. Neuron 62, 53-71. doi: 10.1016/j.neuron.2009.01.034

Cancedda, L., Fiumelli, H., Chen, K., and Poo, M. M. (2007). Excitatory GABA action is essential for morphological maturation of cortical neurons in vivo. J. Neurosci. 27, 5224-5235. doi: 10.1523/JNEUROSCI.5169-06.2007

Carrillo-Reid, L., Han, S., Yang, W., Akrouh, A., and Yuste, R. (2019). Controlling visually guided behavior by holographic recalling of cortical ensembles. Cell 178, 447-457. doi: 10.1016/j.cell.2019.05.045

Carrillo-Reid, L., Yang, W., Bando, Y., Peterka, D. S., and Yuste, R. (2016). Imprinting and recalling cortical ensembles. Science 353, 691-694. doi: 10.1126/ science.aaf7560

Cornejo, V. H., Ofer, N., and Yuste, R. (2022). Voltage compartmentalization in dendritic spines in vivo. Science 375, 82-86. doi: 10.1126/science.abg0501

Fang, W. Q., and Yuste, R. (2017). Overproduction of neurons is correlated with enhanced cortical ensembles and increased perceptual discrimination. Cell Rep. 21, 381-392. doi: 10.1016/j.celrep.2017.09.040

Furukawa, T., Yamada, J., Akita, T., Matsushima, Y., Yanagawa, Y., and Fukuda, A. (2014). Roles of taurine-mediated tonic GABAA receptor activation in the radial migration of neurons in the fetal mouse cerebral cortex. Front. Cell. Neurosci. 8:88. doi: 10.3389/fncel.2014.00088

Gong, Y., Huang, C., Li, J. Z., Grewe, B. F., Zhang, Y., Eismann, S., et al. (2015). High-speed recording of neural spikes in awake mice and flies with a fluorescent voltage sensor. Science 350, 1361-1366. doi: 10.1126/science.aab0810

Graber, D., Imagawa, E., Miyake, N., Matsumoto, N., Miyatake, S., Graber, M., et al. (2021). Polymicrogyria in a child with KCNMA1-related channelopathy. Brain Dev. 44, 173-177. doi: 10.1016/j.braindev.2021.09.009

Guglielmi, L., Servettini, I., Caramia, M., Catacuzzeno, L., Franciolini, F., D'Adamo, M. C., et al. (2015). Update on the implication of potassium channels in autism: $\mathrm{K}(+)$ channelautism spectrum disorder. Front. Cell. Neurosci. 9:34. doi: 10.3389/fncel.2015.00034

Hamm, J. P., Peterka, D. S., Gogos, J. A., and Yuste, R. (2017). Altered cortical ensembles in mouse models of schizophrenia. Neuron 94, 153-167. doi: 10. 1016/j.neuron.2017.03.019

Hanson, M. G., and Landmesser, L. T. (2004). Normal patterns of spontaneous activity are required for correct motor axon guidance and the expression of specific guidance molecules. Neuron 43, 687-701. doi: 10.1016/j.neuron.2004. 08.018

Hardingham, G. E., and Do, K. Q. (2016). Linking early-life NMDAR hypofunction and oxidative stress in schizophrenia pathogenesis. Nat. Rev. Neurosci. 17, 125-134. doi: 10.1038/nrn.2015.19

Hattori, Y., Naito, Y., Tsugawa, Y., Nonaka, S., Wake, H., Nagasawa, T., et al. (2020). Transient microglial absence assists postmigratory cortical neurons in proper differentiation. Nat. Commun. 11:1631. doi: 10.1038/s41467-020-15409-3
Heck, N., Kilb, W., Reiprich, P., Kubota, H., Furukawa, T., Fukuda, A., et al. (2007). GABA-A receptors regulate neocortical neuronal migration in vitro and in vivo. Cereb. Cortex 17, 138-148.

Hevner, R. F. (2006). From radial glia to pyramidal-projection neuron: transcription factor cascades in cerebral cortex development. Mol. Neurobiol. 33, 33-50. doi: 10.1385/MN:33:1:033

Heyes, S., Pratt, W. S., Rees, E., Dahimene, S., Ferron, L., Owen, M. J., et al. (2015). Genetic disruption of voltage-gated calcium channels in psychiatric and neurological disorders. Prog. Neurobiol. 134, 36-54. doi: 10.1016/j.pneurobio. 2015.09.002

Horigane, S. I., Hamada, S., Kamijo, S., Yamada, H., Yamasaki, M., Watanabe, M., et al. (2021). Development of an L-type Ca2+ channel- dependent Ca2+ transient during the radial migration of cortical excitatory neurons. Neurosci. Res. 169, 17-26. doi: 10.1016/j.neures.2020.06.003

Horigane, S. I., Ozawa, Y., Yamada, H., and Takemoto-Kimura, S. (2019). Calcium signalling: a key regulator of neuronal migration. J. Biochem. 165, 401-409. doi: $10.1093 / \mathrm{jb} / \mathrm{mvz} 012$

Horton, N. G., Wang, K., Kobat, D., Clark, C. G., Wise, F. W., Schaffer, C. B., et al. (2013). In vivo three- photon microscopy of subcortical structures within an intact mouse brain. Nat. Photonics 7, 205-209. doi: 10.1038/nphoton.20 12.336

Hubel, D. H., Wiesel, T. N., and LeVay, S. (1977). Plasticity of ocular dominance columns in monkey striate cortex. Philos. Trans. R. Soc. Lond. B Biol. Sci. 278, 377-409. doi: 10.1098/rstb.1977.0050

Iwasato, T., Erzurumlu, R. S., Huerta, P. T., Chen, D. F., Sasaoka, T., Ulupinar, E., et al. (1997). NMDA receptor-dependent refinement of somatotopic maps. Neuron 19, 1201-1210. doi: 10.1016/s0896-6273(00)80412-2

Ji, N., Milkie, D. E., and Betzig, E. (2010). Adaptive optics via pupil segmentation for high-resolution imaging in biological tissues. Nat. Methods 7, 141-147. doi: $10.1038 /$ nmeth. 1411

Kahle, K. T., Khanna, A. R., Duan, J., Staley, K. J., Delpire, E., and Poduri, A. (2016). The KCC2 cotransporter and human epilepsy: getting excited about inhibition. Neuroscientist 22, 555-562. doi: 10.1177/1073858416645087

Kaila, K., Price, T. J., Payne, J. A., Puskarjov, M., and Voipio, J. (2014). Cationchloride cotransporters in neuronal development, plasticity and disease. Nat. Rev. Neurosci. 15, 637-654. doi: 10.1038/nrn3819

Kalia, L. V., Kalia, S. K., and Salter, M. W. (2008). NMDA receptors in clinical neurology: excitatory times ahead. Lancet Neurol. 7, 742-755. doi: 10.1016/ S1474-4422(08)70165-0

Kamijo, S., Ishii, Y., Horigane, S. I., Suzuki, K., Ohkura, M., Nakai, J., et al. (2018). A critical neurodevelopmental role for L-type voltage-gated calcium channels in neurite extension and radial migration. J. Neurosci. 38, 5551-5566. doi: 10.1523/JNEUROSCI.2357-17.2018

Kannan, M., Vasan, G., Huang, C., Haziza, S., Li, J. Z., Inan, H., et al. (2018). Fast, in vivo voltage imaging using a red fluorescent indicator. Nat. Methods 15, 1108-1116. doi: 10.1038/s41592-018-0188-7

Katona, G., Szalay, G., Maák, P., Kaszás, A., Veress, M., Hillier, D., et al. (2012). Fast two-photon in vivo imaging with three-dimensional random-access scanning in large tissue volumes. Nat. Methods 9, 201-208. doi: 10.1038/nmeth. 1851

Katz, L. C., and Shatz, C. J. (1996). Synaptic activity and the construction of cortical circuits. Science 274, 1133-1138. doi: 10.1126/science.274.5290.1133

Kawasaki, H., Iwai, L., and Tanno, K. (2012). Rapid and efficient genetic manipulation of gyrencephalic carnivores using in utero electroporation. $\mathrm{Mol}$ Brain 5:24. doi: 10.1186/1756-6606-5-24

Kawasoe, R., Shinoda, T., Hattori, Y., Nakagawa, M., Pham, T. Q., Tanaka, Y., et al. (2020). Two-photon microscopic observation of cell-production dynamics in the developing mammalian neocortex in utero. Dev. Growth Differ. 62, 118-128. doi: $10.1111 /$ dgd. 12648

Kawauchi, T. (2012). Cell adhesion and its endocytic regulation in cell migration during neural development and cancer metastasis. Int. J. Mol. Sci. 13, 45644590. doi: 10.3390/ijms13044564

Kawauchi, T., and Hoshino, M. (2008). Molecular pathways regulating cytoskeletal organization and morphological changes in migrating neurons. Dev. Neurosci. 30, 36-46. doi: 10.1159/000109850

Kilb, W., and Fukuda, A. (2017). Taurine as an essential neuromodulator during perinatal cortical development. Front. Cell. Neurosci. 11:328. doi: 10.3389/fncel. 2017.00328 
Komuro, H., and Rakic, P. (1996). Intracellular Ca2+ fluctuations modulate the rate of neuronal migration. Neuron 17, 275-285. doi: 10.1016/s0896-6273(00) 80159-2

Kullmann, D. M. (2010). Neurological channelopathies. Annu. Rev. Neurosci. 33, 151-172.

Kumada, T., and Komuro, H. (2004). Completion of neuronal migration regulated by loss of $\mathrm{Ca}(2+)$ transients. Proc. Natl. Acad. Sci. U.S.A. 101, 8479-8484 doi: $10.1073 /$ pnas. 0401000101

Le Guen, Y., Philippe, C., Riviere, D., Lemaitre, H., Grigis, A., Fischer, C., et al. (2019). eQTL of KCNK2 regionally influences the brain sulcal widening: evidence from 15,597 UK Biobank participants with neuroimaging data. Brain Struct. Funct. 224, 847-857. doi: 10.1007/s00429-018-1808-9

Liu, X., Hashimoto-Torii, K., Torii, M., Ding, C., and Rakic, P. (2010). Gap junctions/hemichannels modulate interkinetic nuclear migration in the forebrain precursors. J. Neurosci. 30, 4197-4209. doi: 10.1523/JNEUROSCI. 4187-09.2010

LoTurco, J. J., and Bai, J. (2006). The multipolar stage and disruptions in neuronal migration. Trends Neurosci. 29, 407-413. doi: 10.1016/j.tins.2006.05.006

LoTurco, J. J., Owens, D. F., Heath, M. J., Davis, M. B., and Kriegstein, A. R. (1995). GABA and glutamate depolarize cortical progenitor cells and inhibit DNA synthesis. Neuron 15, 1287-1298. doi: 10.1016/0896-6273(95)90008-x

Maljevic, S., Møller, R. S., Reid, C. A., Pérez-Palma, E., Lal, D., May, P., et al. (2019). Spectrum of GABAA receptor variants in epilepsy. Curr. Opin. Neurol. 32, 183-190. doi: 10.1097/WCO.0000000000000657

Manent, J. B., and Represa, A. (2007). Neurotransmitters and brain maturation: early paracrine actions of GABA and glutamate modulate neuronal migration. Neuroscientist 13, 268-279. doi: 10.1177/1073858406298918

Marín, O. (2012). Cellular and molecular mechanisms controlling the migration of neocortical interneurons. Eur. J. Neurosci. 38, 2019-2029. doi: 10.1111/ejn. 12225

Medvedeva, V. P., and Pierani, A. (2020). How do electric fields coordinate neuronal migration and maturation in the developing cortex? Front. Cell Dev. Biol. 8:580657. doi: 10.3389/fcell.2020.580657

Mire, E., Mezzera, C., Leyva-Díaz, E., Paternain, A. V., Squarzoni, P., Bluy, L., et al. (2012). Spontaneous activity regulates Robol transcription to mediate a switch in thalamocortical axon growth. Nat. Neurosci. 15, 1134-1143. doi: $10.1038 / \mathrm{nn} .3160$

Mizuno, H., Hirano, T., and Tagawa, Y. (2007). Evidence for activity-dependent cortical wiring: formation of interhemispheric connections in neonatal mouse visual cortex requires projection neuron activity. J. Neurosci. 27, 6760-6770. doi: 10.1523/JNEUROSCI.1215-07.2007

Mizuno, H., Hirano, T., and Tagawa, Y. (2010). Pre-synaptic and post-synaptic neuronal activity supports the axon development of callosal projection neurons during different post-natal periods in the mouse cerebral cortex. Eur. J. Neurosci. 31, 410-424. doi: 10.1111/j.1460-9568.2009.07070.x

Mizuno, H., Ikezoe, K., Nakazawa, S., Sato, T., Kitamura, K., and Iwasato, T. (2018). Patchwork-type spontaneous activity in neonatal barrel cortex layer 4 transmitted via Thalamocortical projections. Cell Rep. 22, 123-135. doi: 10. 1016/j.celrep.2017.12.012

Mizuno, H., Luo, W., Tarusawa, E., Saito, Y. M., Sato, T., Yoshimura, Y., et al. (2014). NMDAR-regulated dynamics of layer 4 neuronal dendrites during thalamocorticalreorganization in neonates. Neuron 82, 365-379. doi: 10.1016/j. neuron.2014.02.026

Molyneaux, B. J., Arlotta, P., Menezes, J. R., and Macklis, J. D. (2007). Neuronal subtype specification in the cerebral cortex. Nat. Rev. Neurosci. 8, 427-437. doi: $10.1038 / \mathrm{nrn} 2151$

Nadarajah, B., Alifragis, P., Wong, R. O., and Parnavelas, J. G. (2003). Neuronal migration in the developing cerebral cortex: observations based on real-time imaging. Cereb. Cortex 13, 607-611. doi: 10.1093/cercor/13.6.607

Nakagawa-Tamagawa, N., Kirino, E., Sugao, K., Nagata, H., and Tagawa, Y. (2021). Involvement of Calcium-dependent Pathway and $\beta$ subunit-interaction in Neuronal Migration and Callosal Projection deficits caused by the Cav1.2 I1166T Mutation in Developing Mouse Neocortex. Front. Neurosci. 15:747951. doi: 10.3389/fnins.2021.747951

Ohtaka-Maruyama, C., Okamoto, M., Endo, K., Oshima, M., Kaneko, N., Yura, K., et al. (2018). Synaptic transmission from subplate neurons controls radial migration of neocortical neurons. Science 360, 313-317. doi: 10.1126/science. aar2866
O’Leary, D. D., and Nakagawa, Y. (2002). Patterning centers, regulatory genes and extrinsic mechanisms controlling arealization of neocortex. Curr. Opin. Neurosci. 12, 14-25. doi: 10.1016/s0959-4388(02)00285-4

Ota, K., Oisi, Y., Suzuki, T., Ikeda, M., Ito, Y., Ito, T., et al. (2021). Fast, cellresolution, contiguous-wide two-photon imaging to reveal functional network architectures across multi-modal cortical areas. Neuron 109, 1810-1824. doi: 10.1016/j.neuron.2021.03.032

Paşca, S. P., Portmann, T., Voineagu, I., Yazawa, M., Shcheglovitov, A., Paşca, A. M., et al. (2011). Using iPSC-derived neurons to uncover cellular phenotypes associated with Timothy syndrome. Nat. Med. 17, 1657-1662. doi: 10.1038/nm. 2576

Piatkevich, K. D., Bensussen, S., Tseng, H. A., Shroff, S. N., Lopez-Huerta, V. G., Park, D., et al. (2019). Population imaging of neural activity in awake behaving mice. Nature 574, 413-417. doi: 10.1038/s41586-019-1641-1

Picken Bahrey, H. L., and Moody, W. J. (2003). Early development of voltagegated ion currents and firing properties in neurons of the mouse cerebral cortex. J. Neurophysiol. 89, 1761-1773. doi: 10.1152/jn.00972.2002

Price, D. J., Kennedy, H., Dehay, C., Zhou, L., Mercier, M., Jossin, Y., et al. (2006). The development of cortical connections. Eur. J. Neurosci. 23, 910-920.

Purcell, S. M., Moran, J. L., Fromer, M., Ruderfer, D., Solovieff, N., Roussos, P., et al. (2014). A polygenic burden of rare disruptive mutations in schizophrenia. Nature 506, 185-190. doi: 10.1038/nature12975

Ross, M. E., and Walsh, C. A. (2001). Human brain malformations and their lessons for neuronal migration. Annu. Rev. Neurosci. 24, 1041-1070. doi: 10. 1146/annurev.neuro.24.1.1041

Roussos, P., Mitchell, A. C., Voloudakis, G., Fullard, J. F., Pothula, V. M., Tsang, J., et al. (2014). A role for noncoding variation in schizophrenia. Cell Rep. 9, 1417-1429. doi: 10.1016/j.celrep.2014.10.015

Rubboli, G., Plazzi, G., Picard, F., Nobili, L., Hirsch, E., Chelly, J., et al. (2018). Mild malformations of cortical development in sleep-related hypermotor epilepsy due to KCNT1 mutations. Ann. Clin. Transl. Neurol. 6, 386-391. doi: 10.1002/ acn 3.708

Sasaki, E., Suemizu, H., Shimada, A., Hanazawa, K., Oiwa, R., Kamioka, M., et al. (2009). Generation of transgenic non-human primates with germline transmission. Nature 459, 523-527. doi: 10.1038/nature08090

Schmunk, G., and Gargus, J. J. (2013). Channelopathy pathogenesis in autism spectrum disorders. Front. Genet. 4:222. doi: 10.3389/fgene.2013.00222

Serizawa, S., Miyamichi, K., Takeuchi, H., Yamagishi, Y., Suzuki, M., and Sakano, H. (2006). A neuronal identity code for the odorant receptor-specific and activity-dependent axon sorting. Cell 127, 1057-1069. doi: 10.1016/j.cell.2006. 10.031

Shinmyo, Y., Terashita, Y., Dinh Duong, T. A., Horiike, T., Kawasumi, M., Hosomichi, K., et al. (2017). Folding of the cerebral cortex requires Cdk5 in upper-layer neurons in gyrencephalic mammals. Cell Rep. 20, 2131-2143. doi: 10.1016/j.celrep.2017.08.024

Spitzer, N. C. (2006). Electrical activity in early neuronal development. Nature 444, 707-712. doi: 10.1038/nature05300

Sturman, J. A. (1981). Origin of taurine in developing rat brain. Brain Res. 254, 111-128. doi: 10.1016/0165-3806(81)90063-8

Sturman, J. A., Rassin, D. K., and Gaull, G. E. (1977). Taurine in developing rat brain: maternal-fetal transfer of [35 S] taurine and its fate in the neonate. J. Neurochem. 28, 31-39. doi: 10.1111/j.1471-4159.1977.tb07705.x

Tabata, H., and Nakajima, K. (2003). Multipolar migration: the third mode of radial neuronal migration in the developing cerebral cortex. J. Neurosci. 23, 9996-10001. doi: 10.1523/JNEUROSCI.23-31-09996.2003

Tessier-Lavigne, M., and Goodman, C. S. (1996). The molecular biology of axon guidance. Science 274, 1123-1133.

Tissir, F., and Goffinet, A. M. (2003). Reelin and brain development. Nat. Rev. Neurosci. 4, 496-505

Tochitani, S., Furukawa, T., Bando, R., Kondo, S., Ito, T., Matsushima, Y., et al. (2021). GABAA receptors and maternally derived Taurine regulate the temporal specification of progenitors of excitatory Glutamatergic neurons in the mouse developing cortex. Cereb. Cortex 31, 4554-4575. doi: 10.1093/cercor/ bhab106

Uesaka, N., Hayano, Y., Yamada, A., and Yamamoto, N. (2007). Interplay between laminar specificity and activity-dependent mechanisms of thalamocortical axon branching. J. Neurosci. 27, 5215-5223. doi: 10.1523/JNEUROSCI.468506.2007 
Uhlén, P., Fritz, N., Smedler, E., Malmersjö, S., and Kanatani, S. (2015). Calcium signaling in neocortical development. Dev. Neurobiol. 75, 360-368. doi: 10. 1002/dneu.22273

Villette, V., Chavarha, M., Dimov, I. K., Bradley, J., Pradhan, L., Mathieu, B., et al. (2019). Ultrafast two-photon imaging of a high-gain voltage indicator in awake behaving mice. Cell 179, 1590-1608.e23. doi: 10.1016/j.cell.2019.11.004

Vitali, I., Fièvre, S., Telley, L., Oberst, P., Bariselli, S., Frangeul, L., et al. (2018). Progenitor hyperpolarization regulates the sequential generation of neuronal subtypes in the developing neocortex. Cell 174, 1264-1276.e15. doi: 10.1016/j. cell.2018.06.036

Wang, C. L., Zhang, L., Zhou, Y., Zhou, J., Yang, X. J., Duan, S. M., et al. (2007). Activity- dependent development of callosal projections in the somatosensory cortex. J. Neurosci. 27, 11334-11342. doi: 10.1523/JNEUROSCI.3380-07.2007

Watanabe, M., Zhang, J., Mansuri, M. S., Duan, J., Karimy, J. K., Delpire, E., et al. (2019). Developmentally regulated KCC2 phosphorylation is essential for dynamic GABA-mediated inhibition and survival. Sci. Signal. 12:eaaw9315. doi: 10.1126/scisignal.aaw9315

Weissman, T. A., Riquelme, P. A., Ivic, L., Flint, A. C., and Kriegstein, A. R. (2004). Calcium waves propagate through radial glial cells and modulate proliferation in the developing neocortex. Neuron 43, 647-661. doi: 10.1016/j.neuron.2004. 08.015

Wong, R. O., and Ghosh, A. (2002). Activity-dependent regulation of dendritic growth and patterning. Nat. Rev. Neurosci. 3, 803-812. doi: 10.1038/ nrn941

Yamada, A., Uesaka, N., Hayano, Y., Tabata, T., Kano, M., and Yamamoto, N. (2010). Role of pre- and postsynaptic activity in thalamocortical axon branching. Proc. Natl. Acad. Sci. U.S.A. 107, 7562-7567. doi: 10.1073/pnas. 0900613107

Yang, W., Carrillo-Reid, L., Bando, Y., Peterka, D. S., and Yuste, R. (2018). Simultaneous two-photon imaging and two-photon optogenetics of cortical circuits in three dimensions. eLife 7:e32671. doi: 10.7554/eLife. 32671

Yang, W., Miller, J. E., Carrillo-Reid, L., Pnevmatikakis, E., Paninski, L., Yuste, R., et al. (2016). Simultaneous multi-plane imaging of neural circuits. Neuron 89, 269-284. doi: 10.1016/j.neuron.2015.12.012

Yang, W., and Yuste, R. (2017). In vivo imaging of neural activity. Nat. Methods 14, 349-359. doi: 10.1038/nmeth.4230

Yuryev, M., Pellegrino, C., Jokinen, V., Andriichuk, L., Khirug, S., Khiroug, L., et al. (2016). In vivo calcium imaging of evoked calcium waves in the embryonic cortex. Front. Cell. Neurosci. 9:500. doi: 10.3389/fncel.2015.00500

Zheng, J. Q., and Poo, M. M. (2007). Calcium signaling in neuronal motility. Annu. Rev. Cell Dev. Biol. 23, 375-404. doi: 10.1146/annurev.cellbio.23.090506.123221

Conflict of Interest: The authors declare that the research was conducted in the absence of any commercial or financial relationships that could be construed as a potential conflict of interest.

Publisher's Note: All claims expressed in this article are solely those of the authors and do not necessarily represent those of their affiliated organizations, or those of the publisher, the editors and the reviewers. Any product that may be evaluated in this article, or claim that may be made by its manufacturer, is not guaranteed or endorsed by the publisher.

Copyright (C) 2022 Bando, Ishibashi, Yamagishi, Fukuda and Sato. This is an openaccess article distributed under the terms of the Creative Commons Attribution License (CC BY). The use, distribution or reproduction in other forums is permitted, provided the original author(s) and the copyright owner(s) are credited and that the original publication in this journal is cited, in accordance with accepted academic practice. No use, distribution or reproduction is permitted which does not comply with these terms. 